\title{
Downside-Up Retrograde Dilation for "Lost Cap" Retrieval as a Signature Complication of Esophageal BougieCap Dilation
}

\author{
Vincent Zimmer ${ }^{\mathrm{a}, \mathrm{b}}$

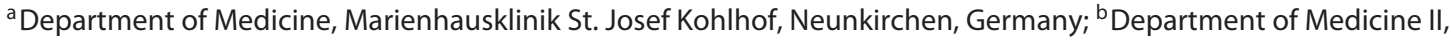 \\ Saarland University Medical Center, Saarland University, Homburg, Germany
}

Keywords

Esophageal stricture · Dilation · Bougienage · BougieCap · Retrieval

\section{Dilatação retrógrada invertida para recuperação de uma "cap perdida" como complicação sinalizadora de uma dilatação esofágica por BougieCap}

\section{Palavras Chave}

Estenose esofágica · Dilatação • Bougienage • BougieCap · Recuperação

A novel device designated BougieCap (Ovesco, Tübingen, Germany) has been marketed for endoscopic treatment of esophageal strictures under both visual and haptic control [1]. A recently published prospective multicenter study on the utility and complications in its mainstay indication has reported high rates of endoscopic and clinical success. On the downside, loss of the BougieCap with subsequent passage into the stool has

\begin{tabular}{ll}
\hline KARGER & (c) 2020 Sociedade Portuguesa de Gastrenterologia \\
& Published by S. Karger AG, Basel \\
karger@karger.com & This article is licensed under the Creative Commons Attribution- \\
www.karger.com/pjg & $\begin{array}{l}\text { NonCommercial-NoDerivatives 4.0 International License (CC BY- } \\
\text { NC-ND) (http://www.karger.com/Services/OpenAccessLicense). } \\
\text { Usage and distribution for commercial purposes as well as any dis- } \\
\text { tribution of modified material requires written permission. }\end{array}$ \\
BOPEN ACCESS &
\end{tabular}

been documented in 2/50 individuals, such that "the lost cap" may be considered a signature complication due to insufficient attachment by circular taping and/or, albeit unproven, stricture length and tightness [2]. While no clinical consequences from the lost caps were reported, potential clinical and/or medicolegal implications may arise reminiscent of small-bowel capsule retention [3].

Against this background, I would like to present the first report of successful lost BougieCap retrieval through a tight radiation-induced upper esophageal stricture. We performed BougieCap dilation in a 78-year-old male patient with high-grade dysphagia due to a complex upper esophageal stricture precluding standard scope passage after definitive radiochemotherapy for squamous cell carcinoma. In a first session, dilation with a 7- and 10$\mathrm{mm}$ BougieCap was performed with guidewire assistance. In another session 4 days apart, 12-, 14-, and 16$\mathrm{mm}$ caps were used without using a guidewire. Highquality mucosal characterization within the stricture through the BougieCap in tight mucosal contact clearly revealed radiation-induced neovascularization without evidence of mucosal relapse (Fig. 1a). However, given the steeper slope at the back of the dome-shaped cap,

Dr. Vincent Zimmer

Department of Medicine, Marienhausklinik St. Josef Kohlhof Klinikweg 1-5

DE-66539 Neunkirchen (Germany)

vincent.zimmer@gmx.de 
Fig. 1. a Endoscopic visualization of the BougieCap procedure with high-quality visualization of the mucosal surface within the stricture with characteristic neovascularization and circular whitening reflective of effective dilation. b "The lost cap" with the attached circular tape sloughed off the scope during withdrawal due to the steeper slope of the asymmetrically dome-shaped cap configuration. $\mathbf{c}$, d Grasping and withdrawal in the esophagus after capture with a Roth net with subsequent axial alignment into the stricture to successfully retrieve the cap in a "downside-up" manner through the stricture ("retrograde dilation") followed by careful oral extraction.
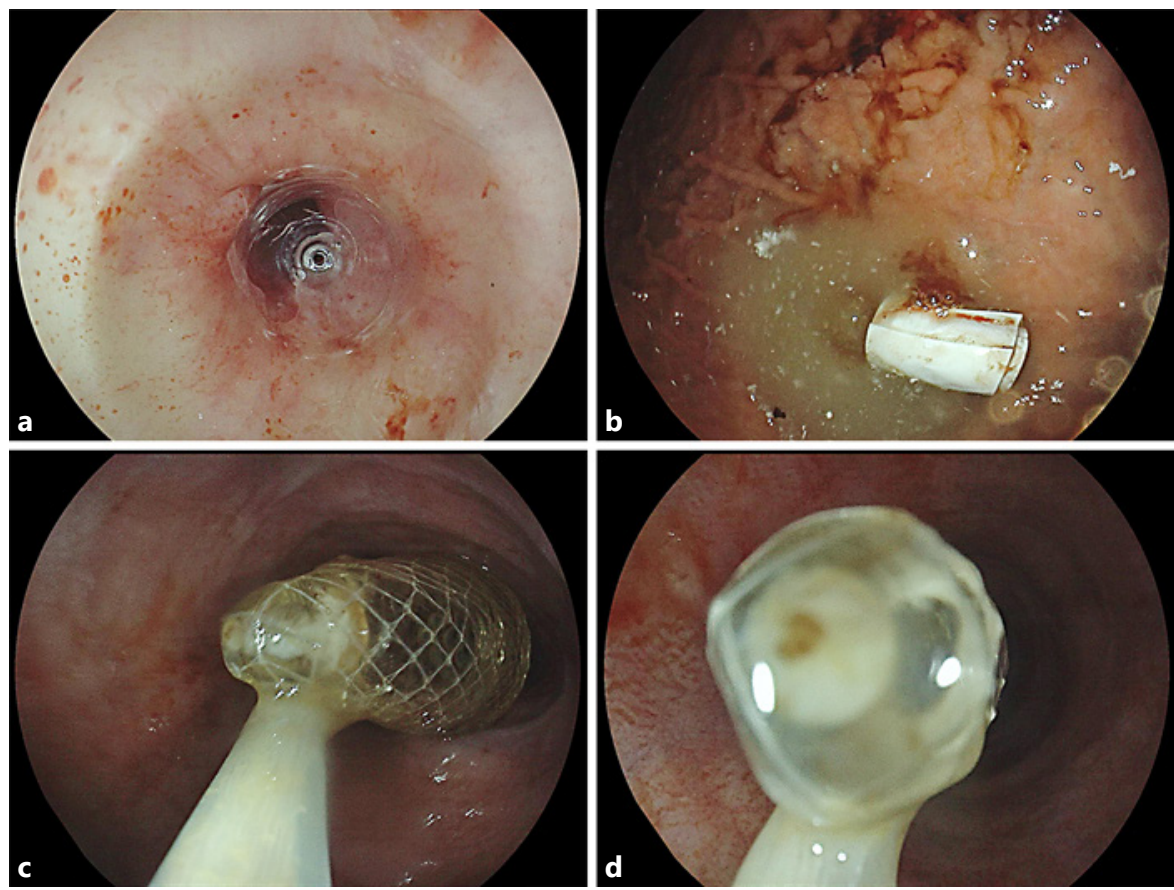

sloughing off the endoscope occurred with immediate gastric migration (Fig. 1b). Retrieval of the cap through the stricture was successful after grasping it with a Roth net in full axial alignment in an "downside-up" manner and careful extraction through the stricture, thus, performing "retrograde dilation" (Fig. 1c, d). Bleeding and/ or perforation could be excluded after retrieval by repeat endoscopy.

\section{Statement of Ethics}

Patient consent has been obtained.

\section{Disclosure Statement} close.

The author declares that he has no conflicts of interest to dis-

\section{References}

1 Cortez-Pinto J, Mão de Ferro S, Dias Pereira A. Use of the novel BougieCap in the treatment of esophageal peptic stricture. Endoscopy. 2019 Sep;51(9):E251-2.

2 Walter B, Schmidbaur S, Rahman I, Albers D, Schumacher B, Meining A. The BougieCap - a new method for endoscopic treatment of complex benign esophageal stenosis: results from a multicenter study. Endoscopy. 2019 Sep;51(9):866-70.

3 Lee HS, Lim YJ, Kim KO, Jang HJ, Chun J, Jeon SR, et al.; Research Group for Capsule
Endoscopy/Small Bowel Endoscopy. Outcomes and Management Strategies for Capsule Retention: A Korean Capsule Endoscopy Nationwide Database Registry Study. Dig Dis Sci. 2019 Nov;64(11):32406. 